\title{
Power reduction coordinated scheme for wind power plants connected with VSC-HVDC
}

\author{
Agustí Egea-Alvarez $^{\mathrm{a}}$, Monica Aragues-Peñalba ${ }^{\mathrm{b}}$, Eduardo Prieto-Araujo $^{\mathrm{b}}$, \\ Oriol Gomis-Bellmunt ${ }^{\mathrm{b}}$ \\ ${ }^{a}$ Siemens Wind Power, G2 8LR Glasgow, UK \\ ${ }^{b}$ CITCEA-UPC, Av. Diagonal 647. 08029 Barcelona, Spain
}

\begin{abstract}
This article introduces a novel power coordination method for the operation under restricted conditions of offshore wind power plants connected with VSC-HVDC without the use of communications between converter stations. The proposed method consists of the coordination of the Dynamic Braking Resistor (DBR) located in the Grid Side Converter (GSC) and the wind power plant in order to maintain the DC voltage stability. The coordination is achieved by means of two droop controllers, one for the GSC-DBR and another one for the offshore wind power plant. These droop gains are selected to avoid limit cycles using the describing function approach. The proposed power coordination scheme is tested and verified by means of dynamic simulations.

Keywords: Power reduction methods, HVDC link, DBR coordination, offshore wind power plant, describing function, droop control.
\end{abstract}




\section{Nomenclature}

\section{Acronyms}

DBR Dynamic Braking Resistor

GSC Grid Side Converter

HVDC High Voltage Direct Current

MPPT Maximum Power Point Tracker

PLL Phase Locked Loop

VSC Voltage Source Converter

WF Wind Farm

WFC Wind Farm Converter

WGC Wind Generator Converter

WT Wind Turbine

WTC Wind Turbine Converter

\section{Controller gains}

$K_{\text {droop }}$ GSC DC droop gain

$K_{H V} \quad$ Droop gain for the GSC-DBR

$k_{i-D C} \quad$ DC controller integral controller gain

$k_{i-i l} \quad$ AC current controller integral controller gain

$k_{i-o l} \quad$ AC Voltage controller integral controller gain

$k_{i-p l l} \quad$ PLL integral controller gain

$k_{p-D C} \quad$ DC controller proportional controller gain

$k_{p-i l} \quad$ AC current controller proportional controller gain

$k_{p-o l} \quad$ AC Voltage controller proportional controller gain

$k_{p-p l l} \quad$ PLL proportional controller gain

$K_{W F} \quad$ Droop gain for the WF power reduction

D Saturation input signal amplitude

W Saturation amplitude

\section{Electrical quantities}

$\delta \quad$ WFC AC voltage angle

$\gamma \quad$ WTC AC voltage angle

$\theta \quad$ Generic electrical angle

$E_{2} \quad$ GSC DC voltage

$E_{1} \quad$ WFC DC voltage

$E_{1}^{\max } \quad$ Maximum voltage threshold for $\mathrm{WF}$ power reduction activation

$E_{1}^{\text {min }}$ Minimum voltage threshold for WF power reduction activation

$E_{2}^{\max }$ Maximum voltage threshold for GSC-DBR activation

$E_{2}^{\min }$ Minimum voltage threshold for GSC-DBR activation

$E_{w t} \quad$ Wind turbine DC bus voltage

$I_{1} \quad$ Current through the HVDC cable

$i_{x} \quad$ Generic electrical current

$i_{c} \quad$ Current through the WFC inductance coupling filter

$I_{\text {in2 }} \quad$ DC current for the GSC
$P_{c h-w t}$ Power dissipated in the WT-DBR

$P_{\text {nom }} \quad$ Wind farm nominal power

$P_{\text {nom }}^{2 c h}$

$P_{n o m}^{w t}$

GSC-DBR nominal power

$p_{w f}^{r e d} \quad$ per unit of the power to be reduced in the wind farm

Pwt Wind turbine actual power

$P_{w t}^{*} \quad$ Wind turbine reference power

$t_{f} \quad$ Minimum fault duration

$v_{x} \quad$ Generic electrical voltage

$v_{c} \quad$ Voltage at AC offshore shunt capacitor

$v_{p} \quad$ Voltage at the WTC terminals

$v_{r} \quad$ Voltage at the aggregated wind turbine cable terminals

$v_{t} \quad$ Voltage applied by the WFC

\section{Electrical parameters}

$C_{C} \quad$ Aggregated $\mathrm{AC} \pi$ equivalent cable capacitor

$C_{f} \quad$ AC offshore LC coupling filter

$C_{x} \quad$ Generic capacitor

$C_{1} \quad$ Equivalent WFC DC capacitor

$C_{2} \quad$ Equivalent GSC DC capacitor

$C_{w t} \quad$ Wind turbine DC bus capacitor

$L_{x} \quad$ Generic inductance

$L_{1} \quad$ Equivalent DC cable inductance

$R_{1} \quad$ Equivalent DC cable resistance

$L_{c} \quad$ AC offshore LC coupling filter inductance

$L_{n} \quad$ Aggregated AC $\pi$ equivalent cable inductance

$L_{p} \quad$ Wind turbine coupling filter inductance

$R_{c} \quad$ AC offshore LC coupling filter resistance

$R_{n} \quad$ Aggregated $\mathrm{AC} \pi$ equivalent cable resistance

$R_{p} \quad$ Wind turbine coupling filter resistance

\section{Subscripts, superscipts and greek letters}

$\Delta \quad$ Variable derivative

$X^{*} \quad$ Superscript for references

$X_{0} \quad$ Subscript for linearization point

$X_{d} \quad$ Subscript for d-axis electrical component

$X_{q} \quad$ Subscript for q-axis electrical component 


\section{Introduction}

Several studies 1, 2, 3, 4] suggest that Voltage Sourced Converter based High Voltage Direct Current (VSC-HVDC) transmission is the preferred technology for the connection of remote offshore wind power plants. HVDC is more cost effective than High Voltage Alternating Current

5 (HVAC) for long distance transmission lines (around $100 \mathrm{~km}$ for cables). VSC is preferred over Line Commutating Converter (LCC-HVDC) technology, for its more reduced footprint required (extremely critical offshore) and for its inherent capability for independent active and reactive power control and grid-forming capability where there is no grid available (offshore). Furthermore, recent developments on Modular Multilevel Converter (MMC) technology are bringing the efficiency of VSC-HVDC technology close to that of LCC technology [5]. The fault ride-through requirements of the system composed by a VSC-HVDC transmission system and a large offshore wind power plant or cluster of wind power plants have been captured the attention of several researchers 6. 1, 8, 9, 10, 11, 12, 13, 14. Severe faults in the main AC grid provoke a sudden restriction of the power export capability on the onshore VSC-HVDC converter which may result in a HVDC voltage increase. In order to avoid overvoltages that could seriously damage the power converter, the incoming active power has to be reduced very rapidly. Different solutions have been proposed [6, 7, 8, 9, 10, 11]:

1. Utilization of a DC resistor in the Grid Side Converter (GSC) to dissipate the excess of power [10, 11, 17, 15]. Nowadays, this DC resistor is present in the major part of HVDC offshore projects as a protection device [16]

2. Reduction of the power generated in the offshore wind power plant. This can be achieved by:

(a) Reducing the electrical power generated by the wind turbines. A communication signal can be sent to all the wind turbines in order to reduce power [17. Optionally, this can be implemented without a dedicated communication system, by using the offshore AC frequency as a communication signal, and allowing the wind turbine to provide frequency response [18]. Once the wind turbine receives the power reduction signal, it can reduce the electrical power either using a chopped DC resistor, which is usually available in the wind turbine DC bus, or by reducing the turbine electrical torque 9 . The latter solution is not preferred because it causes severe mechanical loads in the wind turbine. [17]

(b) Reducing the power generated using the HVDC power converter. This can be theoretically achieved by reducing the voltage of the offshore AC grid emulating a short-circuit. 
However, it seems to be a number of practical limitations [6]. These limitations are related to the large overcurrent which would be provoked in the offshore AC system that may not recommend such solution in practical cases.

It is worth noting that, while the solutions $2 \mathrm{a}$ and $2 \mathrm{~b}$ have an unquestionable academic interest, it is difficult to forecast their real implementation in industrial projects. This is due to the fact that the safety of the overall system totally depends on the proper and fast operation of several cascaded communication and control systems. As solution 1 is the preferred by industrial manufacturers and project developers, the present work focuses on analyzing the proper operation of the overall system for faults in the main AC grid and operation of the system in restricted conditions. For faults in the main AC grid, it will be enough to use the grid-side converter DC resistor to provide fault ridethrough capability and let the offshore system operate as there was no fault. For longer duration restricted conditions, it may also be needed to reduce the active power injected into the main AC grid. Moreover, if the restricted conditions last long enough, the mechanical power generated by the wind turbines will be mostly all reduced, since obviously the DC resistors cannot be rated for continuous operation [17. In those cases, a careful coordination between the onshore VSC-HVDC converter, offshore VSC-HVDC converter and offshore wind turbines (including pitch system and power converters) will be required, taking into account the different nature of the elements involved and the dynamic response they can provide.

The present paper addresses the mentioned power reduction issues and proposes a simple and effective control approach to successfully maintain the overall system stability and smooth response. First, an outline of the modelling and control are presented. Secondly, the power reduction coordinated scheme based on droop controls is introduced. Then, the design of droops gains is widely covered using the describing function analysis tool. The describing function allows determining the minimum controller gains that avoid the limit cycles that exist due to the limited power dissipation of the dynamic braking resistors. To apply the describing function, a linear model is presented in detail (including controllers). Once the linear model is presented, a four-steps methodology based on the describing function to select the droop gains is presented. Finally, the methodology is validated in a case study and the overall system performance is analysed using dynamical simulations. 


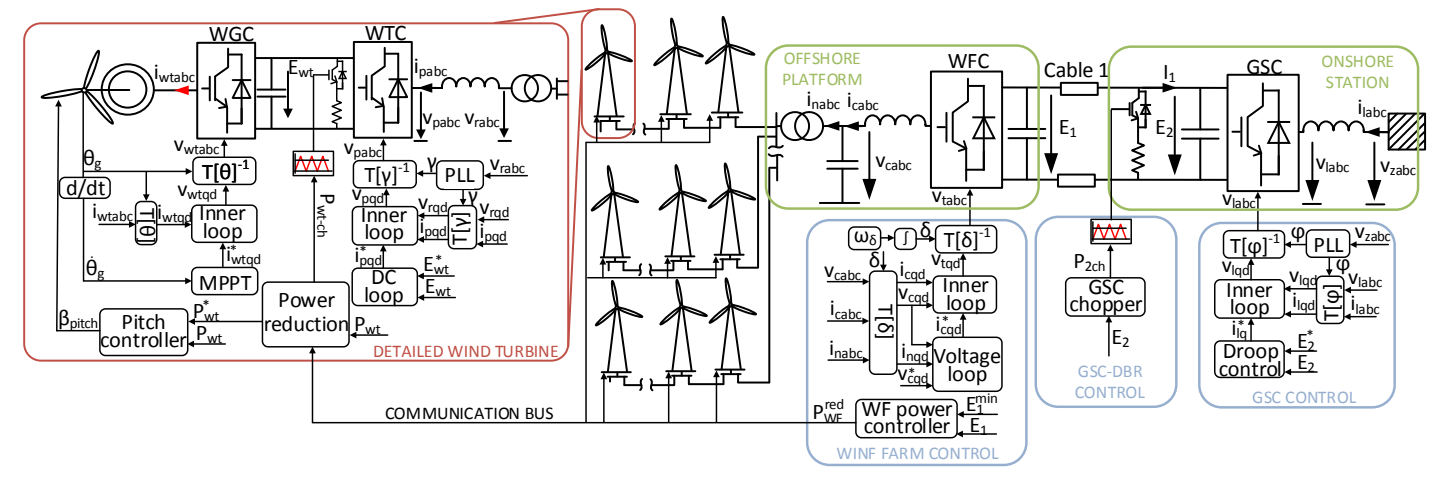

Figure 1: Analysed system and power converter control scheme

\section{Electrical system modelling and control}

In this section, the wind farm and the HVDC link models and their controls. A scheme summarising the model and the different controllers can be seen in Fig. 1 .

\subsection{Electric system}

The system under study consists of an HVDC link based on VSC technology that connects an offshore wind power plant with the main AC grid. A GSC is connected to the AC grid by means of an inductive coupling reactor. Furthermore, the GSC is equipped with an GSC-Dynamic Braking Resistor (GSC-DBR) that permits to dissipate the power that cannot be injected during AC faults. The WFC (Wind Farm Converter) is connected to the wind power plant by means of a LC coupling filter. It allows the control of the wind power plant voltage and the AC current in the inductance. The wind turbines are distributed in arrays and connected to the WFC via a collector. The wind power plant is composed of full power converter wind turbines with an individual WT-DBR and a pitch system. The wind turbine power converter facing the offshore grid is named Wind Turbine Converter (WTC) and the power converter facing the electrical generator is called Wind Generator Converter (WGC).

\subsection{Control system}

\subsubsection{Wind turbine control}

The wind turbine control is divided between the electrical control and the mechanical control. The electrical control is composed of the WGC and the WTC control. The WGC control has an 
inner loop that controls the torque and the flux of the generator [19]. Torque references are given by the outer loop based on a Maximum Power Point Tracker (MPPT) algorithm that calculates the torque to extract the optimal power [20]. The WTC controls the DC bus voltage and the reactive power injected into the $\mathrm{AC}$ grid. There is an inner current control that regulates the current thorough the coupling inductance and an upper level control based on a PI that controls the DC voltage. The controller is grid oriented using a PLL [21]. Furthermore, a WT-DBR is installed in each wind turbine. The mechanical control is a pitch controller that reacts when the electrical generated power $\left(P_{w t}\right)$ exceeds the power reference $\left(P_{w t}^{*}\right)$, usually the nominal power [19].

\subsubsection{Wind power plant voltage control}

The WFC controls the wind power plant AC voltage at the coupling capacitor. The control is implemented using an inner current control that regulates the current through the inductive coupling filter and an outer control loop that controls the voltage at the shunt capacitor. The AC voltage frequency is fixed at a given frequency.

\subsubsection{HVDC Link Control}

The GSC is in charge of the DC link voltage control and the reactive power injected into the grid. The DC voltage is controlled using a droop voltage controller that is designed using the methodology presented in [22]. Another usual approach for DC voltage control for HVDC links is to use a PI Controller. In this article a droop controller is implemented to take advantage of the voltage error produced by the droop control as a communication signal between the GSC and the WFC. The droop voltage control is implemented as

$$
I_{\text {in } 2}^{*}=K_{\text {droop }}\left(E_{2}-E_{2}^{*}\right)
$$

where $E_{2}$ is the DC voltage at the GSC terminals, $I_{i n 2}^{*}$ is the DC current reference for the GSC, and $K_{\text {droop }}$ is the controller gain.

The control of the GSC-DBR and the WT-DBR are discussed in the next section.

\section{Proposed power reduction method}

In this section, a coordinated power reduction method for fault or curtailment situations is proposed. In a case of an $\mathrm{AC}$ contingency, all the generated power cannot be injected to the $\mathrm{AC}$ 
grid due to the GSC current limit. This means that the transmitted power might be not injected to the AC system and it is stored in the capacitors. Consequently, the HVDC link voltage starts to rise. For short faults, it is enough to dissipate the excess power in the GSC-DBR, but for longer contingencies (e.g. the disconnection of a line) it might be not possible to evacuate the excess of power in the GSC-DBR. Therefore, the power should be reduced by the wind turbines.

The proposed power reduction method can be summarised in the following two points: control the GSC-DBR.

For the wind power plant power reduction, it is proposed to use a proportional power reduction curve similar to the GSC-HVDC characteristic. It is defined as

$$
p_{w f}^{r e d}=\frac{E_{1}-E_{1}^{\min }}{E_{1}^{\text {max }}-E_{1}^{\text {min }}}=K_{W F}\left(E_{1}-E_{1}^{\text {min }}\right)
$$


where $p_{w f}^{r e d}$ is the per unit of power needed to be reduced by the wind power plant, $E_{1}^{\text {min }}$ is the minimum voltage action threshold, $E_{1}^{\max }$ is the maximum voltage threshold. These two voltages define the controller gain $K_{W F}=\frac{1}{E_{1}^{\text {max }}-E_{1}^{\text {min }}}$. The power reduction capability of the wind farm is saturated between 0 and 1 to ensure that the dissipated power is within the wind turbine limits.

Since a communication system is not used, the GSC droop control should be tuned to react to higher voltages than the wind power plant droop characteristic. At the same time, the wind power plant power reduction droop should be tuned to react when the voltage is higher than the maximum voltage that can be achieved for the GSC control (GSC droop). Fig. 2 summarizes the action of the GSC droop voltage control characteristic, the power reduction characteristic for the GSC-DBR and the wind power plant power reduction characteristic. The power reduction gain selection is widely discussed in section 4 .

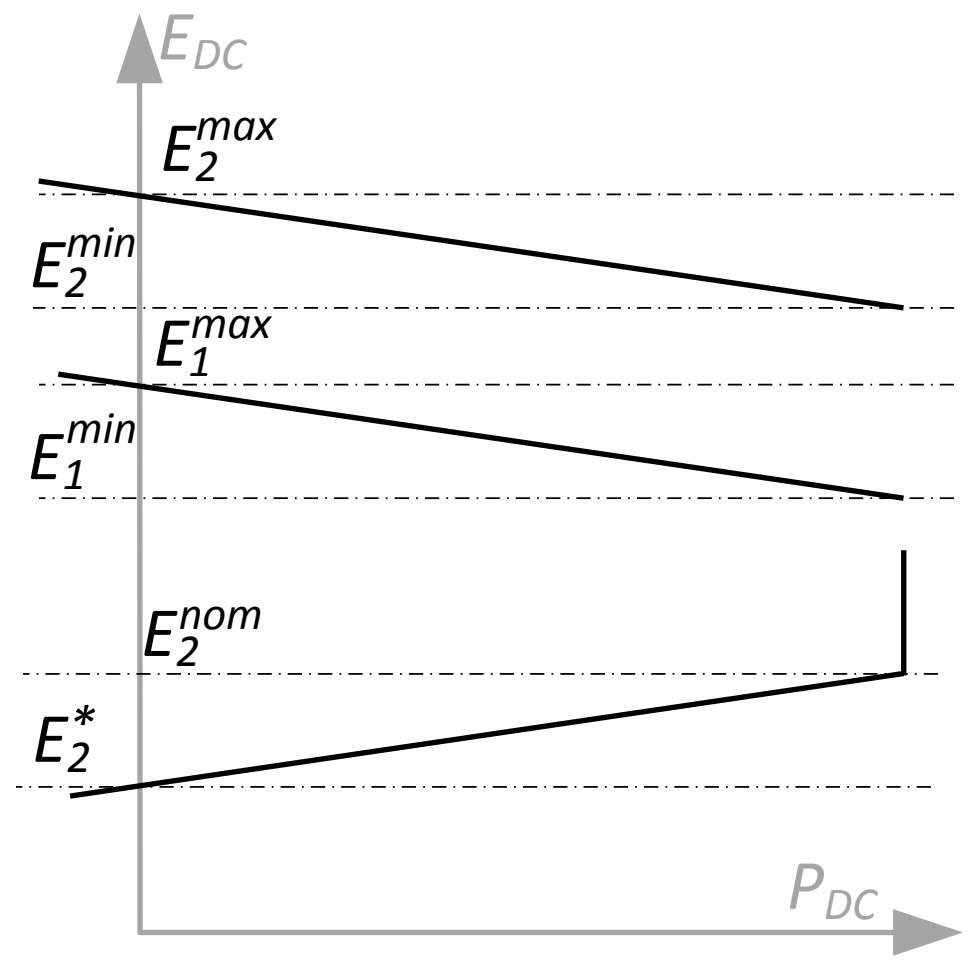

Figure 2: GSC droop, GSC-DBR and WT-DBR characteristics (expressed at the DC terminals of the GSC) 


\subsection{Wind farm power reduction implementation}

The presented wind farm power reduction method needs to be implemented in the offshore wind power plant. The power reduction reference $\left(p_{w f}^{r e d}\right)$ is sent to each wind turbine through the communication system. The generated power in each wind turbine can be reduced using the pitch angle or changing the torque reference in the control system. However, due to the considerable mechanical load effort on the wind turbine when the torque reference is changed suddenly, it is suggested to activate the pitch angle. The pitch angle is combined with the WT-DBR that dissipates the power that cannot be reduced by the pitch mechanism because of its slow dynamics [17, 23]. The power reduction method modifies the pitch controller reference as

$$
P_{w t}^{*}=P_{n o m}^{w t} p_{w f}^{r e d}
$$

where $P_{n o m}^{w t}$ is the wind turbine nominal power. The WT-DBR is controlled to reduce the amount of power that cannot be reduced by the pitch, specially during the first instants that the wind farm power reduction is activated. The power dissipated by the WT-DBR is calculated as

$$
P_{c h-w t}=P_{w t}-P_{w t}^{*}
$$

where $P_{w t}$ is the wind turbine generated power. Furthermore, the power dissipated in the GSC-DBR is calculated as

$$
P_{2 c h}=p_{2 c h}^{r e d} P_{n o m}^{2 c h}
$$

where $P_{n o m}^{2 c h}$ is the GSC-DBR nominal power. The wind power plant power controller is shown in Fig. 1 as an extension of the wind power plant control.

\section{Power reduction controls tuning}

The proposed power reduction method relies on a simple coordination between the GSC and the WFC droop characteristics, but some operational issues can arise if the controller gains are not

properly calculated. Fig. 3 shows the system dynamics with $k_{W T}=\frac{1}{1000}$. As it can be observed, a limit cycle exist in the $E_{2}$ voltage due to the inappropriate gain selection. In this case, the power reduction strategy considered at wind turbine level is the WT-DBR.

The limit cycles presented in Fig. 3 occur because the control action is too aggressive and there is not an equilibrium point due to the actuator saturation (maximum power that can be dissipated 


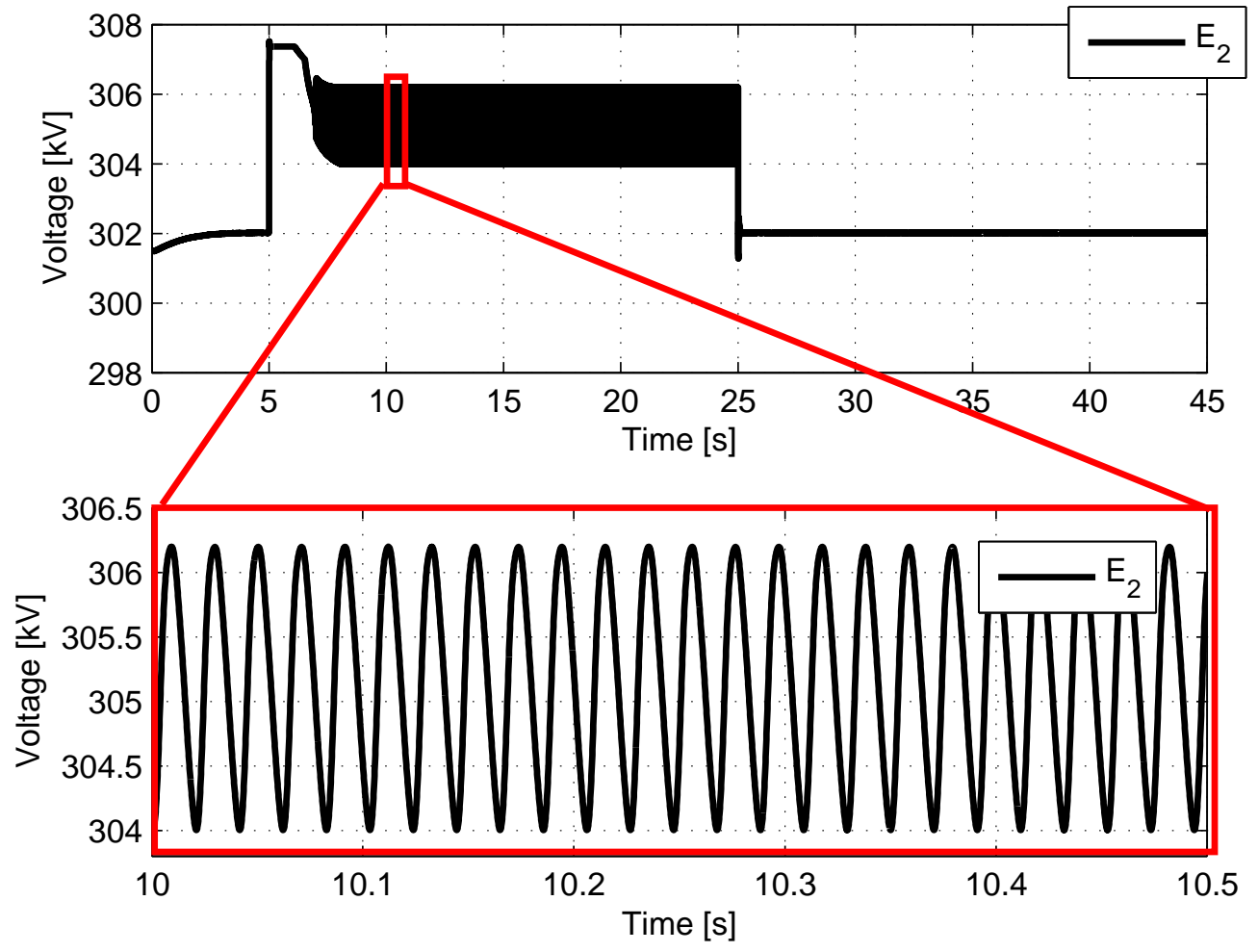

Figure 3: DC voltage at the GSC terminals, $E_{2}$, with a $k_{w t}=\frac{1}{1000}$ (Parameters specified in Table 1 )

in the DBRs). To ensure the appropriate gain selection, the describing function is used. This non-linear analysis tool allows to determine the existence of limit cycles (sustained oscillations) due to the system non-linearities 24. To do so, the characteristic equation of the close loop transfer function of a linear transfer function $(\mathrm{G}(\mathrm{j} \omega))$ and the describing function $(\mathrm{N})$ of the non-linear element (eq. 7) are analyzed. If $\mathrm{N}$ and $\mathrm{G}(\mathrm{j} \omega)$ intersect, a maintained oscillation may exist.

$$
\begin{array}{r}
1+N G(j \omega)=0 \\
G(j \omega)=-\frac{1}{N}
\end{array}
$$

In the present article the analysed non-linearity is the maximum power that can be injected by 


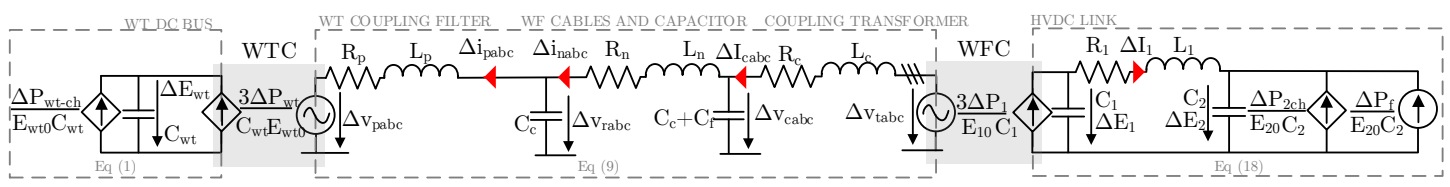

Figure 4: Single-phase and DC system linearised electrical model

the DBRs represented by means of a saturation as

$$
N=\frac{2}{\pi}\left(\sin ^{-1}\left(\frac{W}{D}\right)+\frac{W}{D} \sqrt{1-\left(\frac{W}{D}\right)^{2}}\right)
$$

where $\mathrm{W}$ is the saturation amplitude and $\mathrm{D}$ is the input signal amplitude.

One of the most practical ways to identify the limit cycles is to plot the Nyquist diagram of the linear plant $(G(j \omega))$ and the describing function of the non-linear part $(\mathrm{N})$ and analyse the intersection point. In the analysed case, it is bedded to obtain two transfer functions $(G(j \omega))$, one for the design of $K_{W F}$ and another for the design of $K_{H V}$. For this reason, a linearised model (including controllers) has been developed. The linear model has been developed following a state space approach. The transfer function can be obtained from the state space representation as

$$
\frac{Y(s)}{U(s)}=C(s I-A)^{-1} B+D
$$

where $Y(s)$ and $U(s)$ are the output and input to study and $A, B, C, D$ are the gain matrices of the model. To select the voltage droop gains, the studied transfer functions are the relationship between the power dissipated in the WT-DBR $\left(P_{c h-w t}\right)$ and voltage at the WFC terminal $\left(E_{1}\right)$, $G_{1}(j \omega)=\frac{E_{1}(s)}{P_{c h-w t(s)}}$, and the power dissipated in the GSC-DBR $(P 2 c h)$ and the voltage at the GSC terminals $\left(E_{2}\right), G_{2}(j \omega)=\frac{E_{2}(s)}{P_{2 c h(s)}}$.

This model consists of: a wind turbine aggregated model, a collection grid aggregated model and a HVDC link.

Power converters have been modelled using the averaged low-frequency model, consisting of three $\mathrm{AC}$ voltage source on the $\mathrm{AC}$ side and a current source on the $\mathrm{DC}$ side 25]. Fig. 4 shows the linearised electrical scheme.

AC contingencies are modelled as power unbalances between the aggregated wind turbine model 
and the GSC by means of a constant power source in the HVDC system. From this assumption, the GSC control and the WGC control are not required and the studied system is simplified.

\subsection{Linearised electric model equations}

\subsubsection{Linearised wind turbine aggregated model equations}

The linearised wind turbine aggregation consists of a model where all the wind farm wind turbines have been aggregated in a single model. It consists of the wind turbine DC bus, the WTDBR and the wind turbine grid side converter. WT-DBR is modelled as a linearised power source expressed as a current source. The wind generator and the machine side converter have been not modelled because the machine dynamics are slower compared to the rest of system dynamics due to the large rotor inertia [26. The linearised wind turbine state-space model is based on [19] and it is defined as

$$
\begin{array}{rr}
\Delta \dot{x}_{w}= & A_{w} \Delta x_{w}+B_{w} \Delta u_{w} \\
\Delta y_{w}= & C_{w} \Delta x_{w}
\end{array}
$$

where the matrix gains are

$$
\begin{aligned}
& A_{w}=\quad\left[\frac{-P_{w t 0}}{C_{w t} E_{w t 0}^{2}}+\frac{-P_{w t-c h 0}}{C_{w t} E_{w t 0}^{2}}\right] \\
& B_{w}=\quad\left[\begin{array}{ll}
\frac{1}{C_{w t} E_{w t 0}} & \frac{1}{C_{w t} E_{w t 0}}
\end{array}\right]^{T} \\
& C_{w}=
\end{aligned}
$$

where the state, inputs and output vectors are

$$
\begin{aligned}
\Delta x_{w} & =\left[\Delta E_{w t}\right] \\
\Delta u_{w} & =\left[\Delta P_{w t} \Delta P_{c h-w t}\right]^{T} \\
\Delta y_{w} & =\left[\Delta E_{w t}\right]
\end{aligned}
$$

where $C_{w t}$ is the aggregated wind turbine capacitor, $E_{w t}$ is the wind turbine DC bus voltage, $P_{w t}$ is power injected by the wind turbine converter and $P_{c h-w t}$ is the power injected by the WT-DBR.

\subsubsection{Wind power plant grid linearised model}

The linearised wind power plant grid is modelled in $q d$ reference frame and consists of an aggregated wind turbine inductive coupling filter impedance $\underline{Z}_{p}=R_{p}+\jmath \omega L_{p}$, an aggregated $\pi$ 
equivalent cable model, where $C_{c}$ is the shunt capacitor and $\underline{Z}_{n}=R_{n}+\jmath \omega L_{n}$ is the line impedance and the LC coupling filter for the WFC, where $C_{f}$ is the shunt capacitor at power converter PCC and $\underline{Z}_{c}=R_{c}+\jmath \omega L_{c}$ is the power converter reactor. The model is based on [27. The state space model is

$$
\begin{gathered}
\Delta \dot{x}_{w f}=\left[A_{w f 1} \mid A_{w f 2}\right] \Delta x_{w f}+B_{w f} \Delta u_{w f} \\
\Delta y_{w f}=\left[\frac{I_{10}}{\overline{C_{w f 1}}}\right] \Delta x_{w f}+\left[\frac{0_{10,4}}{D_{w f 1}}\right] \Delta u_{w f} \\
A_{w f 1}=\left[\begin{array}{ccccc}
-\frac{R_{p}}{L_{p}} & -\omega & \frac{1}{L_{p}} & 0 & 0 \\
\omega & -\frac{R_{p}}{L_{p}} & 0 & \frac{1}{L_{p}} & 0 \\
-\frac{1}{C_{f}} & 0 & 0 & -\omega & \frac{1}{C_{f}} \\
0 & -\frac{1}{C_{f}} & \omega & 0 & 0 \\
0 & 0 & -\frac{1}{L_{n}} & 0 & -\frac{R n}{L_{n}} \\
0 & 0 & 0 & -\frac{1}{L_{n}} & \omega \\
0 & 0 & 0 & 0 & -\frac{1}{C_{c}+C_{f}} \\
0 & 0 & 0 & 0 & 0 \\
0 & 0 & 0 & 0 & 0 \\
0 & 0 & 0 & 0 & 0
\end{array}\right] \\
A_{w f 2}=\left[\begin{array}{ccccc}
0 & 0 & 0 & 0 & 0 \\
0 & 0 & 0 & 0 & 0 \\
-\frac{R_{n}}{L_{n}} & 0 & \frac{R n}{L_{n}} & 0 & 0 \\
0 & 0 & -\omega & \frac{1}{C_{c}+C_{f}} & 0 \\
\frac{1}{C_{c}+C_{f}} & \omega & 0 & 0 & \frac{1}{C_{c}+C_{f}} \\
0 & -\frac{1}{L_{c}} & 0 & -\frac{R_{c}}{L_{c}} & -\omega \\
0 & 0 & -\frac{1}{L_{c}} & \omega & -\frac{R_{c}}{L_{c}}
\end{array}\right]
\end{gathered}
$$




$$
\begin{aligned}
B_{w f}= & {\left[\begin{array}{cccc}
-\frac{1}{L_{p}} & 0 & 0 & 0 \\
0 & -\frac{1}{L_{p}} & 0 & 0 \\
& & z \operatorname{eros}(6,4) & \\
0 & 0 & \frac{1}{L_{c}} & 0 \\
0 & 0 & 0 & \frac{1}{L_{c}}
\end{array}\right] } \\
C_{w f 1}= & {\left[\begin{array}{cccc}
\frac{3}{2} v_{p q 0} & 0 \\
\frac{3}{2} v_{p d 0} & 0 \\
z \operatorname{zeros}(6,2) & \\
0 & \frac{3}{2} v_{c q 0} \\
D_{w f 1}= & \frac{3}{2} v_{c d 0}
\end{array}\right]^{T} } \\
& {\left[\begin{array}{cccc}
\frac{3}{2} i_{c q 0} & \frac{3}{2} i_{c d 0} & 0 & 0 \\
0 & 0 & \frac{3}{2} i_{c q 0} & \frac{3}{2} i_{c d 0}
\end{array}\right] }
\end{aligned}
$$

190

and the state and input vectors are,

$$
\begin{aligned}
& x_{l c}=\left[\Delta i_{p q} \Delta i_{p d} \Delta v_{r q} \Delta v_{r d} \Delta i_{n q}\right. \\
& \left.\Delta i_{n d} \Delta v_{c q} \Delta v_{c d} \Delta i_{c q} \Delta i_{c d}\right]^{T} \\
& u_{l c}=\left[\Delta v_{p q} \Delta v_{p d} \Delta v_{t q} \Delta v_{t d}\right]^{T} \\
& y_{l c}=\left[\Delta i_{p q} \Delta i_{p d} \Delta v_{r q} \Delta v_{r d} \Delta i_{n q} \Delta i_{n d}\right. \\
& \left.\Delta v_{c q} \Delta v_{c d} \Delta i_{c q} \Delta i_{c d} \Delta P_{w t} \Delta P_{1}\right]^{T}
\end{aligned}
$$

where $v_{p q d}$ is the voltage at the WTC terminals, $i_{p q d}$ is the current injected by the WTC, $v_{r q d}$ is the voltage at the aggregated wind turbine cable terminals, $i_{n q d}$ is the current through the cable, $v_{c q d}$ is the voltage at the coupling shunt capacitor, $i_{c q d}$ is the current through the inductance coupling filter, $v_{t q d}$ is the voltage applied by the WFC and $P_{1}$ is the power injected into the HVDC link.

\subsubsection{HVDC link linearised equations}

The HVDC link is modelled as $\pi$ equivalent, where $C_{1}$ and $C_{2}$ are the shunt capacitors that is the sum of the DC capacitor filter at the converter terminals and the cable equivalent capacitor, 
and $R_{1}$ and $L_{1}$ is the equivalent cable resistance and inductance. The GSC-DBR has been modelled as a linearised power source. The model has been based on [28] and its state space representation is

$$
\begin{gathered}
\Delta \dot{x}=\left[\begin{array}{ccc}
-\frac{P_{10}}{C_{1} E_{10}^{2}} & \frac{1}{C_{1}} & 0 \\
\frac{1}{L_{1}} & -\frac{R_{1}}{L_{1}} & -\frac{1}{L_{1}} \\
0 & \frac{1}{C_{2}} & -\frac{P_{2 c h 0}}{C_{2} E_{20}^{2}}-\frac{P_{f 0}}{C E_{20}^{2}}
\end{array}\right] \Delta x_{h v}+ \\
{\left[\begin{array}{ccc}
\frac{1}{C_{1} E_{10}} & 0 & \frac{1}{C_{1} E_{20}}
\end{array}\right]^{T} \Delta u_{h v}} \\
\Delta y=\left[\begin{array}{lll}
1 & 0 & 0 \\
0 & 0 & 1
\end{array}\right] \Delta x_{h v}
\end{gathered}
$$

where the state, inputs and output vectors are

$$
\begin{aligned}
& \Delta x_{h v}=\left[\begin{array}{lll}
\Delta E_{1} & \Delta I_{1} & \Delta E_{2}
\end{array}\right]^{T} \\
& \Delta u_{h v}=\left[\begin{array}{ll}
\Delta P_{1} & \Delta P_{2 c h}
\end{array}\right]^{T} \\
& \Delta y_{h v}=\left[\begin{array}{ll}
\Delta E_{1} & \Delta E_{2}
\end{array}\right]^{T}
\end{aligned}
$$

where $I_{1}$ is the current through the HVDC cable and $P_{2 c h}$ is the power injected by the GSC-DBR. $P_{f}$ aims to simplify the linearised model, reducing the number of system inputs considering a fault as a power unbalance between the power that can be injected into the $\mathrm{AC}$ grid and the generated power. To demonstrate the validity of this simplification, if the voltage at GSC converter terminals $\left(E_{2}\right)$ is compared to the equivalent during a fault the error is below a $1.3 \%$.

\subsection{Linearised control equations}

The control equations need to be linearised to be able to use the standard engineering tools. The majority of the controllers are linear but the effect of the power system angle should be taken into account. The connection between the linearised electrical model and the controllers is shown in Fig. 5. This figure compared to Fig. 1, shows the linearised model and controls interact during a fault in the AC side: the GSC is not represented because during a fault it is saturated and the wind turbine control is slower compared to the rest of controllers. 


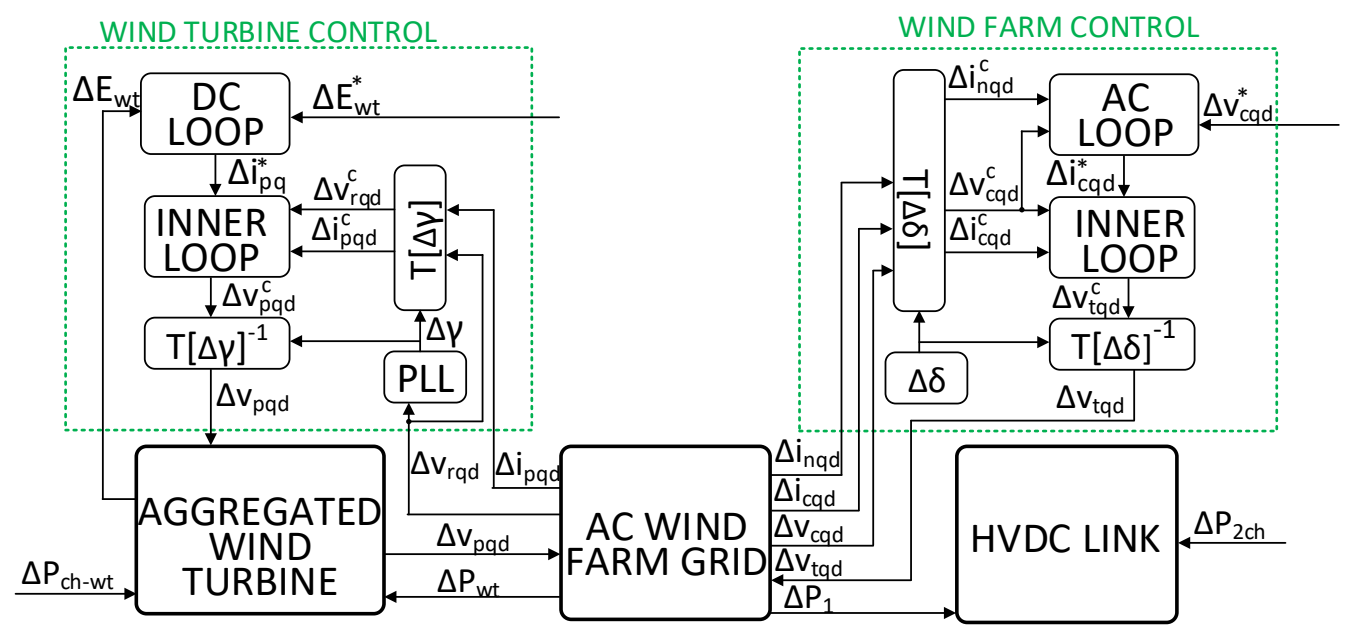

Figure 5: Connection of the electrical linearised equations and the control linearised equations

\subsubsection{Linearised Park transformation and inverse-transformation equations}

Park transformation allows the transformation of the three-phase $a b c$ quantities into the synchronous reference $q d$ frame. It is linearised to include the effect of the angle variation. The linearised Park transformation is given by,

$$
\left[\Delta x_{q d}^{c}\right]=\left[T_{q d}\right]\left[\Delta x_{q d} \Delta \theta\right]^{T}
$$


where $\left[T_{q d}\right]$ is

$$
\left[T_{q d}\right]=\left[\begin{array}{ccc}
\cos \left(\theta_{0}\right) & -\sin \left(\theta_{0}\right) & -\sin \left(\theta_{0}\right) x_{q 0}-\cos \left(\theta_{0}\right) x_{d 0} \\
\sin \left(\theta_{0}\right) & \cos \left(\theta_{0}\right) & \cos \left(\theta_{0}\right) x_{q 0}-\sin \left(\theta_{0}\right) x_{d 0}
\end{array}\right]
$$

and the linearised inverse transformation is,

$$
\left[\Delta x_{q d}\right]=\left[T_{q d}\right]^{-1}\left[\Delta x_{q d}^{c} \Delta \theta\right]^{T}
$$

where $\left[T_{q d}\right]^{-1}$ is

$$
\left[T_{q d}\right]^{-1}=\left[\begin{array}{ccc}
\cos \left(\theta_{0}\right) & \sin \left(\theta_{0}\right) & \cos \left(\theta_{0}\right) x_{d 0}-\sin \left(\theta_{0}\right) x_{q 0} \\
-\sin \left(\theta_{0}\right) & \cos \left(\theta_{0}\right) & -\cos \left(\theta_{0}\right) x_{q 0}-\sin \left(\theta_{0}\right) x_{d 0}
\end{array}\right]
$$

where $x$ is the transformed electrical variable. The transformed variables are indicated with the superscript ${ }^{\prime}$.

\subsubsection{Current loop equations}

The vector current control allows to control the voltage through an inductance applying a given voltage in its terminals. It requires the measure of the current and the voltage on the ending terminals. The state-space representation is,

$$
\begin{aligned}
& \Delta \dot{x}_{i l}=\left[\begin{array}{cccccc}
-1 & 0 & 1 & 0 & 0 & 0 \\
0 & -1 & 0 & 1 & 0 & 0
\end{array}\right] \Delta u_{i l} \\
& \Delta y_{i l}=\left[\begin{array}{cc}
k_{i-i l} & 0 \\
0 & k_{i-i l}
\end{array}\right] \Delta x_{i l}+ \\
& {\left[\begin{array}{cccccc}
-k_{p-i l} & 0 & k_{p-i l} & -\omega L_{x} & 1 & 0 \\
0 & -k_{p-i l} & \omega L_{x} & k_{p-i l} & 0 & 1
\end{array}\right] \Delta u_{i l}}
\end{aligned}
$$

where $k_{i-i l}$ and $k_{p-i l}$ are the integral and proportional current controller gains and $L_{x}$ is a generic inductance where the current is controlled. The state variables, inputs and outputs are,

$$
\begin{aligned}
\Delta x_{i l} & =\left[\Delta e i_{x q}^{c} \Delta e i_{x d}^{c}\right]^{T} \\
\Delta u_{i l} & =\left[\Delta i_{x q}^{*} \Delta i_{x d}^{*} \Delta i_{x q}^{c} \Delta i_{x d}^{c} \Delta v_{h q}^{c} \Delta v_{h d}^{c}\right]^{T} \\
\Delta y_{i l} & =\left[\Delta v_{l q}^{c} \Delta v_{l d}^{c}\right]^{T}
\end{aligned}
$$


The subscript " $x$ " refers to a generic controlled variable, $v_{h q d}$ is the node with the highest voltage and $v_{l q d}$ is the voltage with the lowest voltage. $\Delta e i_{x q d}$ is the current error, defined as the difference between $\Delta i_{x q d}^{*}$ and $\Delta i_{x q d}$. The inner loop has been tuned according to [30].

\subsubsection{Voltage loop controller}

The voltage loop is used to control the current across a shunt capacitor injecting a given amount of current. It requires the voltage of the capacitor and the output line current measurement. The state space representation is,

$$
\begin{aligned}
& \Delta \dot{x}_{o l}=\left[\begin{array}{cccccc}
-1 & 0 & 1 & 0 & 0 & 0 \\
0 & -1 & 0 & 1 & 0 & 0
\end{array}\right] \Delta u_{o l} \\
& \Delta y_{o l}=\left[\begin{array}{cc}
k_{i-o l} & 0 \\
0 & k_{i-o l}
\end{array}\right] \Delta x_{o l}+ \\
& {\left[\begin{array}{cccccc}
-k_{p-o l} & 0 & k_{p-o l} & -\omega C_{x} & 1 & 0 \\
0 & -k_{p-o l} & \omega C_{x} & k_{p-o l} & 0 & 1
\end{array}\right] \Delta u_{o l}}
\end{aligned}
$$

where $k_{p-o l}$ and $k_{i-o l}$ are the proportional and integral controller gains and $C_{x}$ is the generic capacitor where the voltage is controlled. The state variables, inputs and outputs are

$$
\begin{aligned}
\Delta x_{o l} & =\left[\Delta e v_{x q} \Delta e v_{x d}\right]^{T} \\
\Delta u_{o l} & =\left[\Delta v_{x q}^{*} \Delta v_{x d}^{*} \Delta v_{x q}^{c} \Delta v_{x d}^{c} \Delta i_{o q}^{c} \Delta i_{o d}^{c}\right]^{T} \\
\Delta y_{o l} & =\left[\Delta i_{i q}^{*} \Delta i_{i q}^{*}\right]^{T}
\end{aligned}
$$

$i_{i q d}$ are the current references and $i_{\text {oqd }}$ is the current at the output line. $\Delta e v_{x q d}$ is the voltage error, defined as the difference between $\Delta v_{x q d}^{*}$ and $\Delta v_{x q d}$.

\subsubsection{Wind turbine DC Voltage controller}

The wind turbine DC bus voltage controller is based on a PI controller that calculates the $i_{p q}^{*}$ current loop setpoint as $G_{e-w t}(s)=\frac{k_{p-D C} s+k_{i-D C}}{s}$ where $k_{p-D C}$ and $k_{i-D C}$ are the proportional and the integral gains. The controller parameters can be tuned according to 31.

\subsection{Controller gains selection}

As it has been shown in Fig. 5 gains $K_{W F}$ and $K_{H V}$ should be tuned ensuring an appropriate 
the power converters and cables. A four-step methodology is presented to determine the value of $E_{1}^{\min }, E_{1}^{\max }, E_{2}^{\min }$ and $E_{2}^{\max }$ :

$E_{1}^{\text {min }}$ Selection. - $E_{1}^{\text {min }}$ is selected to activate the wind power plant power reduction immediately after the saturation of the GSC if the fault lasts more than a few seconds. It means that $E_{1}^{\text {min }}$ should be close to the maximum voltage that can be reached during normal operation. This value is calculated determining the maximum voltage $E_{2}$ during normal operation as

$$
\begin{gathered}
P_{2}^{\text {nom }}=I_{G S C} E_{2}^{\text {nom }}=K_{\text {droop }}\left(E_{2}^{\text {nom }}-E_{2}^{*}\right) E_{2}^{\text {nom }} \\
E_{2}^{\text {nom }}=\frac{\sqrt{4 K_{\text {droop }} P_{\text {nom }}+E_{2}^{* 2}+E_{2}^{*} K_{\text {droop }}}}{2 K_{\text {droop }}}
\end{gathered}
$$

where $P_{n o m}$ is the power converter nominal power and $E_{2}^{\text {nom }}$ is the $E_{2}$ voltage when $P_{\text {nom }}$ is injected. Once the maximum voltage $E_{2}$ is determined, the voltage at the WFC terminals, $E_{1}$, is calculated considering the voltage droop at the resistance. This value is the minimum value that $E_{1}^{\min }$ can have. It is calculated as

$$
E_{1}^{\text {min }} \geq \frac{P_{\text {nom }}}{E_{2}^{\text {nom }}} R_{1}+E_{2}^{\text {nom }}
$$

It is suggested to leave a dead-band between the calculated minimum level and the selected minimum value.

$E_{1}^{\max }$ Selection. - $E_{1}^{\max }$ is the maximum voltage that defines the $K_{W F}$. This is the most critical value due to the possible DC voltage limit cycle caused by the multiple different dynamics and controllers that are installed between the wind turbines and the WFC.

The design of the $K_{W F}$ is carried out considering that all the power is dissipated in the WTDBT, at least for a certain period as it is explained in section 3.1. It means that the voltage $E_{1}$ is controlled by using the WT-DBR. The droop gain is selected analysing the frequency response of the transfer function between the $P_{w t-c h}$ and $E_{1}$. This can be obtained from the mathematical manipulation of the equations presented in Section 4.1 and 4.2 and connected following the diagram presented in Fig. 5. Fig. 6 a) shows the block diagram of the studied closed loop system. During the $K_{W F}$ design phase, it is assumed that GSC-DBR is not acting.

Fig. 7 shows the frequency response of the transfer function, $G_{1}(j \omega)=\frac{E_{1}(s)}{P_{c h-w t(s)}}$, and the trajectory of the saturation describing function for different $K_{W F}$ gain values. The saturation trajectory has been plotted according to 9 considering a saturation amplitude (W) of $P_{c h-w t}^{n o m}$ for a 


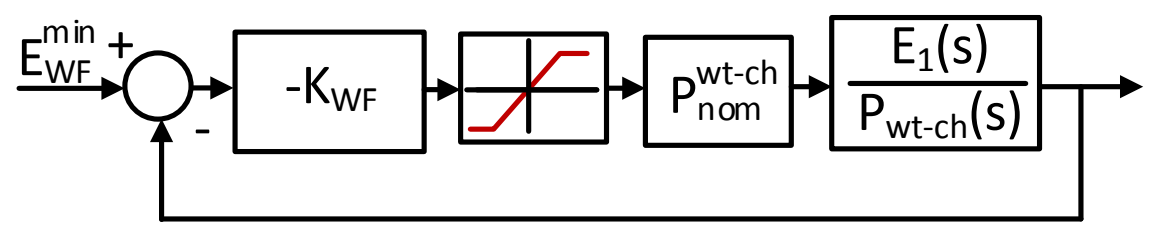

a)

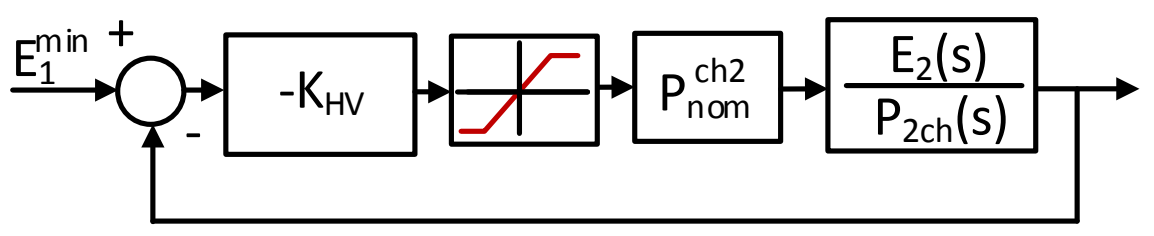

b)

Figure 6: Block diagrams used to study the effects of the saturations

vector of different input signal amplitudes (D). As it can be observed, for values of $K_{W F}$ smaller than $1 / 2700$ the limit cycle and the $G_{1}(j \omega)$ frequency response are not crossing for the studied case (see parameters in Table 1). According to the describing function analysis on the Nyquist diagram, if the two lines are not crossing, there might not be limit cycles [24].

$E_{2}^{\text {min }}$ Selection. To avoid the connection of GSC-DBR during long faults, when the wind turbine power reduction is acting, the $E_{2}^{\min }$ should be tuned in order to start to act when the $E_{1}^{\max }$ is surpassed. This minimum voltage occurs when the system transfers nominal power. It can be calculated as

$$
P_{\text {nom }}=\frac{E_{1}^{\max }-E_{2}^{\min }}{R_{1}} E_{2}^{\min }
$$

where $E_{2}^{\min }$ is

$$
E_{2}^{\text {min }} \geq \frac{\sqrt{E_{1}^{\max ^{2}}-4 P_{\text {nom }} R_{1}}+E_{1}^{\max }}{2}
$$

It is suggested to add a dead band to this minimum threshold in order to avoid interactions between controllers.

$E_{2}^{\max }$ Selection. $E_{2}^{\max }$ is selected using the same procedure used to determine $E_{1}^{\max }$. In this case the studied transfer function is the relationship between the HVDC bus voltage and the power 


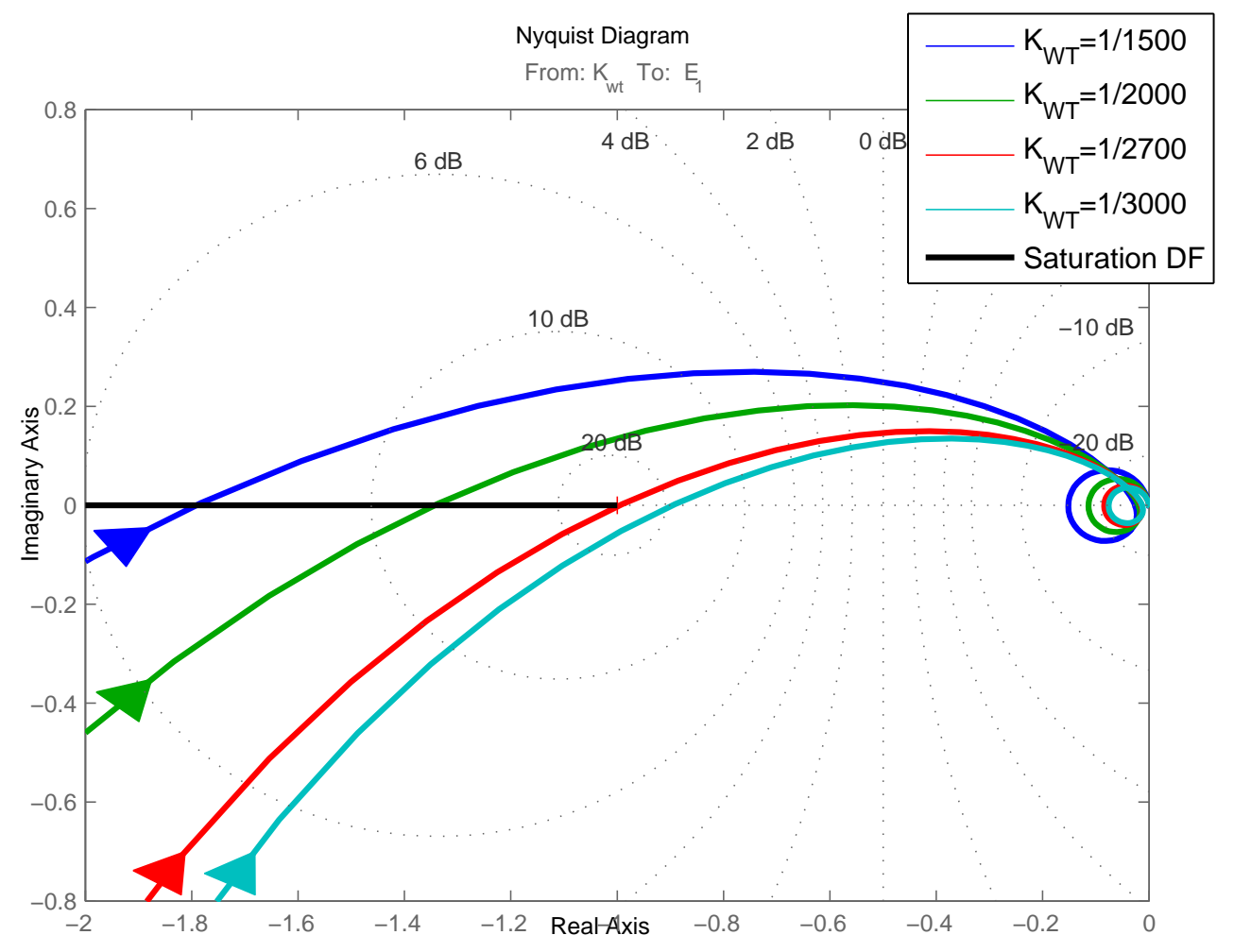

Figure 7: Nyquist plot used to determine the limit cycle limit for the $K_{W T}$ gain

dissipated by the GSC-DBR $G_{2}(j \omega)=\frac{E_{2}(s)}{P 2 c h(s)}$. In this case, the saturation amplitude (W) is $P_{n o m}^{2 c h}$.

should be lower than $K_{H V}=\frac{1}{500}$ in order to avoid limit cycles.

\section{Simulation results}

To test the proposed control scheme, a simulation scenario has been performed in MATLAB/Simulink ${ }^{\circledR}$ software and the SimPowerSystem library using the system model presented in Fig. 1. A full power converter aggregated model has been used to simplify the simulation. An aggregated model of 20 wind turbines of $5 \mathrm{MW}$ is considered. The wind turbine model has been inspired in 32 . The power converters have been simulated considering an average model.

This simulation scenario consists of a $80 \%$ power restriction in the power that can be injected 


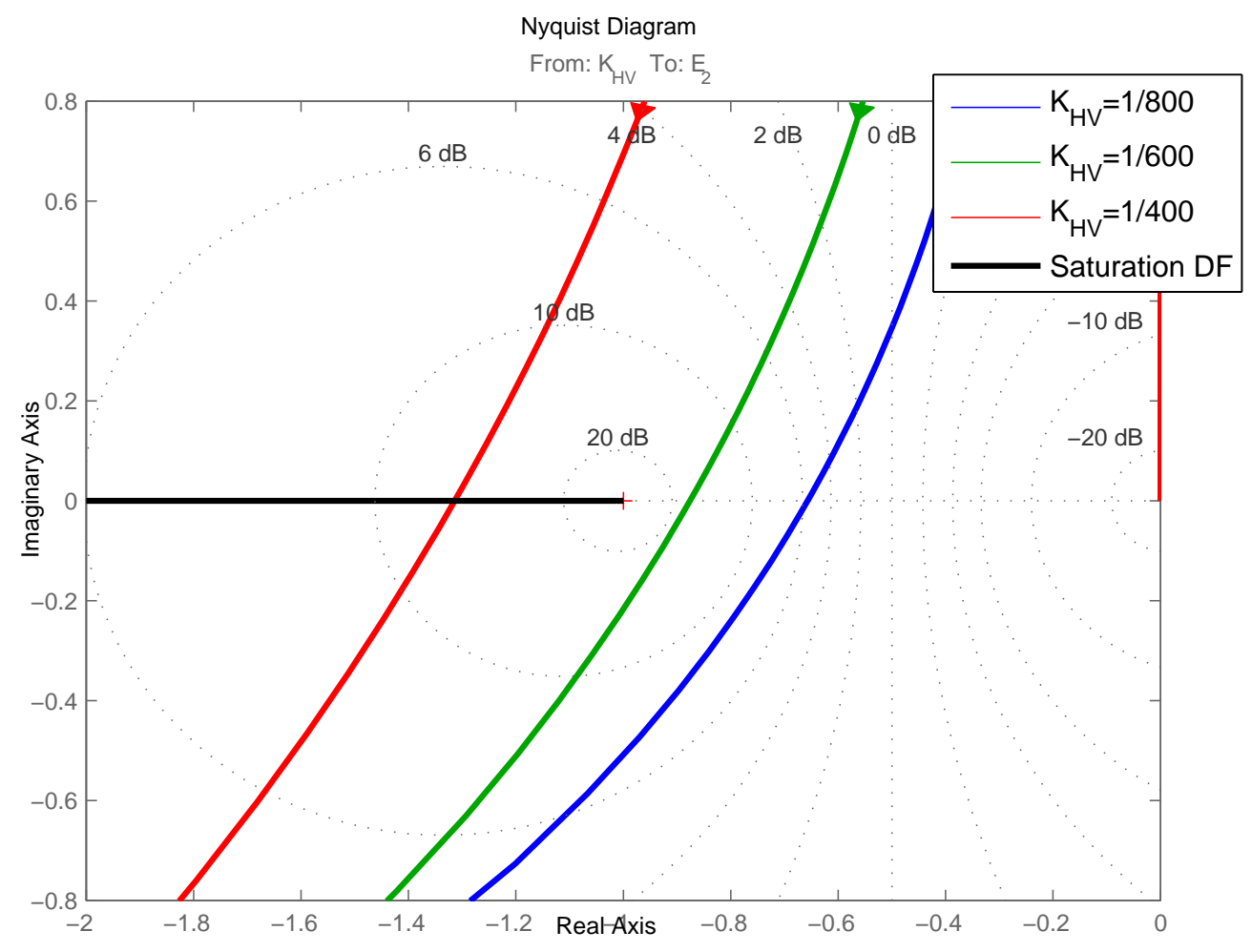

Figure 8: Nyquist plot used to determine the limit cycle limit for the $K_{H V}$ gain

by the GSC (e.g. due to a trip line) during $20 \mathrm{~s}$, starting at $\mathrm{t}=5 \mathrm{~s}$ and finishing at $\mathrm{t}=25 \mathrm{~s}$. Simulation parameters can be seen in Table 1.

Fig. 9 shows the voltage and the power during the pre-fault, the fault and the recovery. As it can be observed before the fault, the droop control action is controlling the DC voltage. When the power restriction occurs, the DC voltage rises intermediately, and the GSC-DBR starts to dissipate the power that cannot be injected. Because the fault lasts more than 1 second, the WTC begins to reduce the generated power gradually. First, the pitch reference is changed to be adapted to the new power reduction reference. Because the pitch mechanism has slow dynamics, the WT-DBR dissipates the power difference that cannot be reduced by the pitch during $t=6 \mathrm{~s}$ and $\mathrm{t}=10 \mathrm{~s}$. As it can be observed, the WT-DBR is gradually reducing the dissipated power. At $t=25 \mathrm{~s}$, the power restriction is cleared and the system returns to work to normal conditions. The total amount of 


\begin{tabular}{lll}
\hline Value & Parameter & Unit \\
\hline$E_{2}^{*}$ & 300 & {$[\mathrm{kV}]$} \\
$P_{\text {nom }}$ & 100 & {$[\mathrm{MW}]$} \\
$\underline{\mathrm{Z}}_{p}=R_{p}+\jmath \omega X_{p}$ & $0.25+\jmath 1.57$ & {$[\Omega]$} \\
$\underline{\mathrm{Z}}_{n}=R_{n}+\jmath \omega X_{p}$ & $0.502+\jmath 1.025$ & {$[\Omega]$} \\
$\underline{\mathrm{Z}}_{c}=R_{c}+\jmath \omega X_{c}$ & $0.35+\jmath 1.1$ & {$[\Omega]$} \\
$C_{f}$ & 15 & {$[\mu \mathrm{F}]$} \\
$C_{c}$ & 2.1 & {$[\mu \mathrm{F}]$} \\
$C_{1}$ & 150 & {$[\mu \mathrm{F}]$} \\
$R_{1}$ & 1.5 & {$[\Omega]$} \\
$L_{1}$ & 6.8 & {$[\mathrm{mH}]$} \\
$k_{d r o o p}$ & $1 / 10$ & {$[\mathrm{~A} / \mathrm{V}]$} \\
$E_{1}^{\text {max }}$ & 307 & {$[\mathrm{kV}]$} \\
$E_{1}^{\text {min }}$ & 304 & {$[\mathrm{kV}]$} \\
$E_{2}^{\text {max }}$ & 307.7 & {$[\mathrm{kV}]$} \\
$E_{2}^{\text {min }}$ & 307.1 & {$[\mathrm{kV}]$} \\
$v_{\text {wind }}$ & 12 & {$[\mathrm{~m} / \mathrm{s}]$} \\
$t_{f}$ & 1 & {$[\mathrm{~s}]$} \\
\hline & & \\
\hline
\end{tabular}

Table 1: Electrical and control parameters used in the simulation

energy dissipated in the WTs-DBR is $95 \mathrm{MJ}$ and the energy dissipated in the GSC-DBR is $120 \mathrm{MJ}$ for the analysed case.

Fig. 10 shows the voltage evolution on the power steady state characteristics. The main operation points are:

(1) Before the fault, the system is regulated by means of the GSC voltage droop.

(2) The power is not controlled due to the GSC saturation and the injected power is reduced drastically.

(3) Once the $E_{2}^{\min }$ is surpassed, the GSC-DBR starts to dissipate power and a new equilibrium point is reached. 

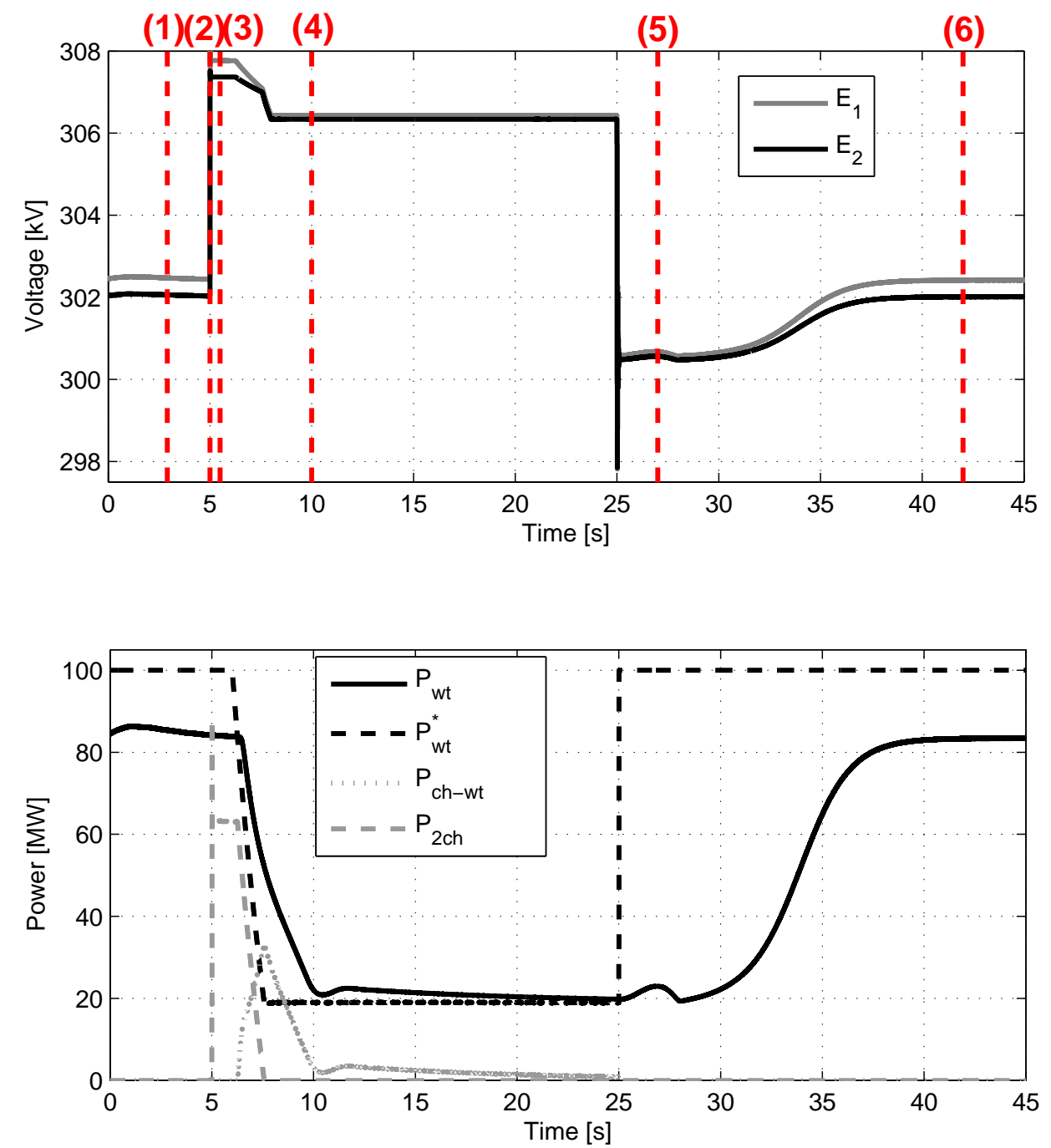

Figure 9: $E_{1}$ and $E_{2}$ voltage and power evolution

(4) Because the fault lasts for more than $t_{f}$, the WF power reduction starts to act and the DC voltage is moved from the GSC-DBR control to the WF power control. In point (4) a new steady-state is reached.

(5) Once the fault is cleared, the system is controlled back by the GSC droop characteristic. 
(6) After some time, the system returns to point (1).

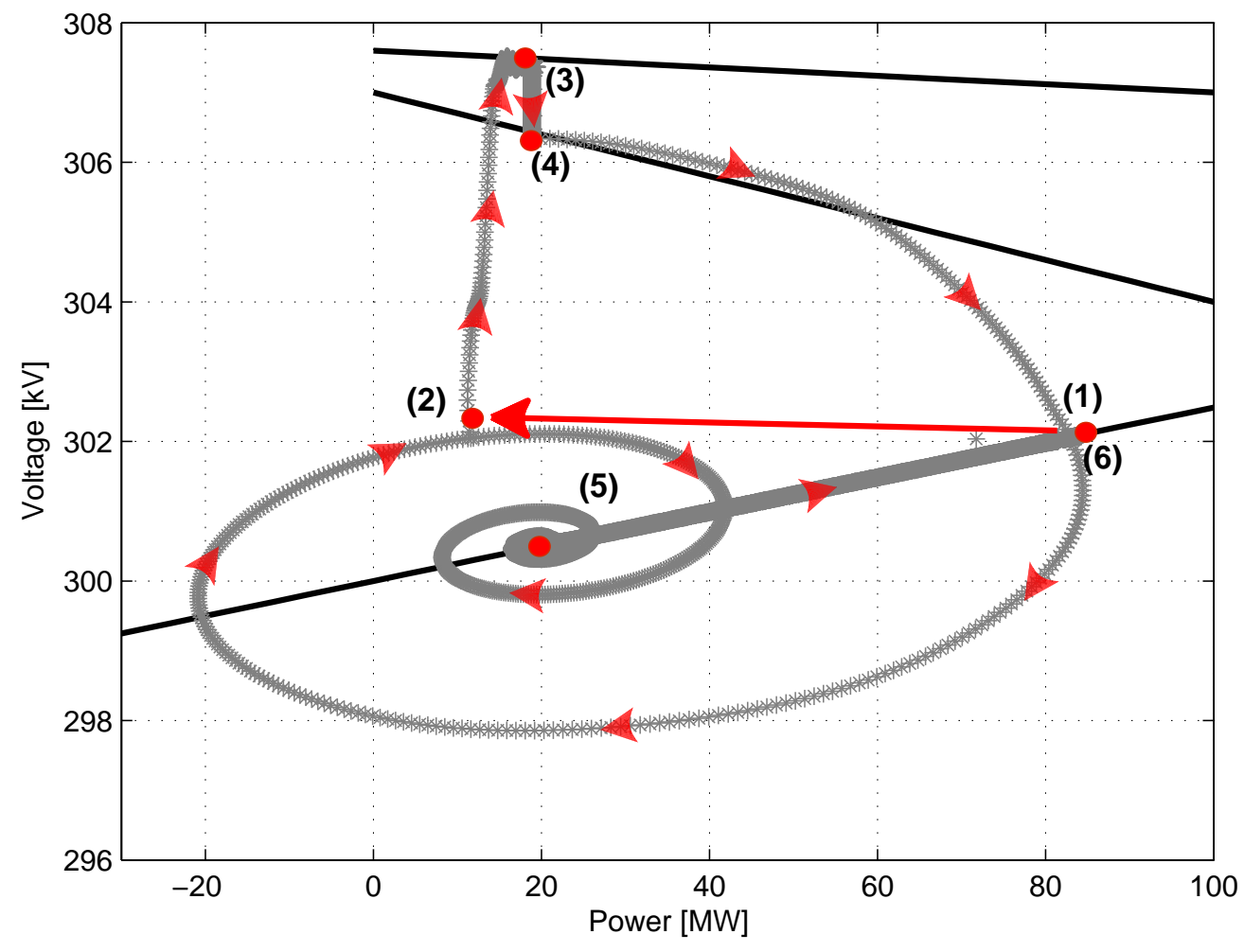

Figure 10: $E_{2}$ trajectory on the steady state characteristics (WF characteristic have been moved to $E_{2}$ values)

\section{Conclusion}

This paper has introduced a coordinated power reduction method for faulty operation scenarios. The presented method allows the fault right through and the operation in restricted conditions of an HVDC link combining an GSC-DBR and the wind power plant generated power reduction capability. The proposed solution does not require a communication system between the two converter stations. To design the controllers, the non-linear describing function analysis tool has been used and a fourstep methodology to determine the controller gains has been presented. A linearised model of the HVDC link is presented and used to analyse the controller. The coordinated power reduction scheme has been evaluated under computer-based dynamic simulation and the proposed scheme 
shows a good performance.

\section{Acknowledgments}

335 project ENE2015-67048-C4-1-R.

\section{References}

[1] O. Gomis-Bellmunt, A. Egea-Alvarez, A. Junyent-Ferre, J. Liang, J. Ekanayake, N. Jenkins, Multiterminal hvdc-vsc for offshore wind power integration, in: PES General Meeting, 2011 IEEE, 2011

[2] N. B. Negra, J. Todorovic, T. Ackermann, Loss evaluation of HVAC and HVDC transmission solutions for large offshore wind farms, Electric Power Systems Research 76 (11) (2006) 916 927.

[3] D. V. Hertem, M. Ghandhari, Multi-terminal vsc-hvdc for the european supergrid: Obstacles, Renewable and Sustainable Energy Reviews 14 (9) (2010) 3156 - 3163.

[4] R. Pinto, P. Bauer, S. Rodrigues, E. Wiggelinkhuizen, J. Pierik, B. Ferreira, A novel distributed direct-voltage control strategy for grid integration of offshore wind energy systems through mtdc network, IEEE Trans. Ind. Electron. 60 (6) (2013) 2429-2441.

[5] H. Saad, S. Dennetire, J. Mahseredjian, P. Delarue, X. Guillaud, J. Peralta, S. Nguefeu, Modular multilevel converter models for electromagnetic transients, IEEE Transactions on Power Delivery 29 (3) (2014) 1481-1489.

[6] G. Ramtharan, A. Arulampalam, J. Ekanayake, F. Hughes, N. Jenkins, Fault ride through of fully rated converter wind turbines with ac and dc transmission systems, IET Renewable Power Generation 3 (2009) 426-438(12).

[7] S. Chaudhary, R. Teodorescu, P. Rodriguez, P. Kjar, Chopper controlled resistors in vsc-hvdc transmission for wpp with full-scale converters, in: IEEE PES/IAS Conference on Sustainable Alternative Energy (SAE) 2009, 2009, pp. 1-8. doi:10.1109/SAE.2009.5534882. 
[8] L. Xu, L. Yao, C. Sasse, Grid integration of large dfig-based wind farms using vsc transmission, IEEE Trans. Power Syst. 22 (3) (2007) 976-984.

[17] A. Perdana, Dynamic models of wind turbines, Ph.D. thesis, Chalmers University of Technology (2008).

[18] L. Xu, L. Yao, DC voltage control and power dispatch of a multi-terminal HVDC system for integrating large offshore wind farms, IET Renewable Power Generation 5 (3) (2011) 223-233. 
[19] F. D. Bianchi, H. De Battista, R. J. Mantz, Wind turbine control systems: principles, modelling and gain scheduling design, Springer, 2006.

[20] K. Tan, S. Islam, Optimum control strategies in energy conversion of pmsg wind turbine system without mechanical sensors, IEEE Trans. Energy Convers. 19 (2) (2004) 392-399.

[21] S.-K. Chung, A phase tracking system for three phase utility interface inverters, IEEE Trans. Power Electron. 15 (3) (2000) 431-438.

[22] E. Prieto-Araujo, A. Egea-Alvarez, S. Fekriasl Fekri, O. Gomis-Bellmunt, Dc voltage droop control design for multi-terminal hvdc systems considering ac and dc grid dynamics, Power Delivery, IEEE Transactions on early acces.

[23] M. Nasiri, J. Milimonfared, S. Fathi, A review of low-voltage ride-through enhancement methods for permanent magnet synchronous generator based wind turbines, Renewable and Sustainable Energy Reviews 47 (2015) 399 - 415. doi:http://dx.doi.org/10.1016/j.rser. 2015.03.079.

URL http://www.sciencedirect.com/science/article/pii/S1364032115002324

[24] J. J. Slotine, W. Li, Applied Nonlinear Control, 1991.

[25] E. Prieto-Araujo, F. Bianchi, A. Junyent-Ferre, O. Gomis-Bellmunt, Methodology for droop control dynamic analysis of multiterminal vsc-hvdc grids for offshore wind farms, IEEE Trans. Power Del. 26 (4) (2011) $2476-2485$.

[26] J. Conroy, R. Watson, Aggregate modelling of wind farms containing full-converter wind turbine generators with permanent magnet synchronous machines: transient stability studies, IET Renewable Power Generation 3 (1) (2009) 39-52.

[27] V. Akhmatov, Analysis of dynamic behavior of electric power systems with large amount of wind power, Ph.D. thesis, Technical University of Denmark (2003).

[28] L. Zhang, L. Harnefors, H.-P. Nee, Modeling and control of vsc-hvdc links connected to island systems, Power Systems, IEEE Transactions on 26 (2) (2011) 783-793.

[29] L. Zhang, Modeling and control of vsc-hvdc links connected to weak ac systems, Ph.D. thesis, KTH (2010). 
[30] A. Egea-Alvarez, A. Junyent-Ferre, O. Gomis-Bellmunt, Active and reactive power control of grid connected distributed generation systems, in: L. Wang (Ed.), Modeling and Control of Sustainable Power Systems, Green Energy and Technology, Springer Berlin Heidelberg, 2012, pp. $47-81$.

[31] F. D. Bianchi, O. Gomis-Bellmunt, Droop control design for multi-terminal VSC-HVDC grids based on LMI optimization, in: Proc. of the 50th Conference on Decision and Control, 2011, pp. $4823-4828$.

[32] A. M. Hemeida, W. A. Farag, O. A. Mahgoub, Modeling and control of direct driven pmsg for ultra large wind turbines, World Academy of Science, Engineering and Technology 59 (2011) 918-924. 